\title{
Estimating saproxylic beetle (Coleoptera: Cerambycidae and Buprestidae) diversity in Bukit Timah Nature Reserve, Singapore, with a methodological and biological review
}

\author{
L.F. Cheong \\ Lee Kong Chian Natural History Museum \\ Conservatory Drive, Singapore 117377 \\ eleclf@nus.edu.sg
}

\begin{abstract}
Approximately one third of all forest insect species worldwide depend directly or indirectly on dying or dead wood (i.e., they are saproxylic). They are a highly threatened ecological group but the status of many species remains undocumented. There is an urgent need to develop a better appreciation for the diversity and ecology of saproxylic insects so as to inform management strategies for conserving these organisms in tropical forests. Two of the historically better studied beetle groups, Cerambycidae and Buprestidae, are highlighted with a brief discussion of the methods for studying them and their ecology, and a systematic attempt to survey these two beetle groups in the Bukit Timah Nature Reserve, Singapore, is described. From a comparison with the historical data, it is inferred that the decline of the saproxylic insect fauna must be happening at a rate that would certainly be considered alarming if only it were more widely noticed. Finally, the implications for overall conservation of the insect fauna and of the reserve are considered.
\end{abstract}

Keywords. Alfred Wallace, Insects, invertebrate conservation, species diversity, woodborers

\section{Introduction}

The comprehensive biodiversity survey of the 163 ha Bukit Timah Nature Reserve (BTNR), Singapore, has been introduced by Chan \& Davison (2019). A survey of saproxylic beetles in the nature reserve was included, the most comprehensive such work since the time of A.R. Wallace.

The urgency and magnitude of assessing local insect biodiversity requires us to make appropriate use of suitable sampling techniques. The method that is used in this project is fast, simple, and cheap, both because time is of the essence and also because of the shortage of manpower and local resources. It represents a compromise between the inventory type of approach and the more ecology-oriented sampling techniques. Inventory-related techniques basically try to maximise the number of species discovered in a given sampling area. They typically involve a 'hit-and-run' style of survey that often fails to take into account factors such as relative abundance or the inherent bias of the sampling behaviour. On the other hand, the ecology-oriented sampling techniques emphasise statistical tractability and therefore usually involve 
methods such as automated traps or rigorously defined sampling units such as plots. These kinds of techniques tend to represent the local fauna poorly. For this beetle survey, the aim was to obtain a fair representation of the total saproxylic beetle richness on the one hand, and yet on the other, to achieve a degree of statistical tractability, so that data obtained from different sites or over different years can potentially be compared. For detailed analysis of the results, two charismatic saproxylic beetle groups (long-horned beetles Cerambycidae and jewel beetles Buprestidae) are described, for which enough historical data exist.

\section{Background}

Well over $50 \%$ of all known living organisms (plants and animals) are insects (Chapman, 2009). The number of described insect species has recently broken the 1 million mark (Foottit \& Adler, 2017), whereas the total number of insect species that actually exist could be in the range of 5-10 million (Ødegaard, 2000). Their tremendous diversity makes it possible for insects to inhabit all habitats and biotopes on the whole planet. The paradox and values of insects in conservation stem from their vast abundance and their taxonomic and biological diversity. On the one hand, insects are vastly more speciose and contribute by far the largest number of taxa to biodiversity relative to plants or other animals. They are ubiquitous, displaying an unparalleled diversity of life-history strategies and occurring in virtually all ecological niches. Insects also have short generation times, rapid population growth, and respond nearly in concert with environmental perturbation. This means that insects are good indicators of areas of high conservation value for other organisms. A park or nature reserve that is managed or designed with proper consideration given to insects would most likely note, and respond to, differences and changes in insect populations. Such sensitive management would pay rich dividends for other organisms as well.

On the other hand, the bewildering variety of insects can be a barrier to understanding. The detailed ecology of most species is likely to be fragmentary or even non-existent. Often, specimen collection records are not recent, and many individuals cannot be identified to species level. To tackle the conservation of a large order such as Coleoptera or Hymenoptera, even just in Singapore where the species number is already in the range of several thousands, might be quite overwhelming. This can be seen in the current bias in worldwide conservation research (Clark \& May, $2002)$, with vertebrate studies predominating (69\% of research papers though they account for only $3 \%$ of described species) over plants ( $20 \%$ of papers versus $18 \%$ of species), and with invertebrates lagging far behind (11\% of papers versus $79 \%$ of species).

The Singapore Red Data Book (Davison et al., 2008) includes assessments of the conservation status of relatively few groups of easily recognised species of insects. These groups include the Order Lepidoptera (butterflies only), the Order Phasmida (stick insects) and the Order Odonata (damselflies and dragonflies). Status assessments for many other taxa, however, are extremely difficult to complete. Often, 
there are few, if any, taxonomic experts in Singapore for a given insect group. For many insect groups, there is also a lack of collections rich enough to document the decline or extirpation of a particular insect species. Despite these challenges, the essence of conservation action plans is not to wait for complete information, but to assemble informed professional opinion and best current data with a willingness to embrace uncertainty and adapt as knowledge advances, especially for insect groups where there are clear signs of problems. It is also erroneous to assume 'not enough information' exists for some charismatic beetle families such as long-horned beetles and jewel beetles. Historical information on their distributions, combined with local field experience and knowledge of pertinent threats, should enable reasonable working hypotheses on the conservation status of a large percentage of species. In this paper, the saproxylic beetles are used as an example to show that there exist sufficient historical records to demonstrate clear signs of severe population decline or even outright extirpation.

Saproxylic insects are insects that are associated with dead wood or with the fungi and microorganisms that decompose it, as well as the associated predators, parasitoids and commensals. They play an important role in a critical ecological process, the recycling of nutrients in forest. Insects, not earthworms as generally supposed, are the principal turners and renewers of the forest soil. Saproxylic insects are a major component of forest biodiversity and contain representatives from all the major orders, but beetles and flies are especially well represented among them. For example, $56 \%$ of all forest beetles are associated with dead wood in Central Europe (Köhler, 2000), 35\% in boreal forests in Finland, and 33\% in lowland tropical forests of Sulawesi (Hanski \& Hammond, 1995).

Different saproxylic species participate in the decomposition of bark, bast and wood during different phases in the course of micro-succession. These saproxylic insects often have narrow resource requirements and presumably would be harmed by resource loss. These requirements include tree species, degree of decay, level of sun exposure, the species of wood-decaying fungi colonising the wood, etc. There is general agreement that saproxylic species are disproportionately threatened with extinction worldwide due to loss of old-growth forests and hence they are gazetted in various national red lists (Berg et al., 1995; Shirt, 1987). Many saproxylic species now survive in Europe only as relictual populations, "hanging on by the tips of their tarsi" (Grove, 2002) in small patches of forest or pasture woodland. While faunistic knowledge about these saproxylic insects in Singapore is patchy, a valuable historical snapshot is provided by Alfred Wallace's beetle collection at Bukit Timah about 150 years ago (Pascoe, 1864-1869), a collection that included both Cerambycidae and Buprestidae.

\section{Biology of Cerambycids and Buprestids}

Cerambycidae are characterised by having each antenna nearly always at least half as long as the body. All are plant feeders. Most larvae feed on the solid tissues of plants, 
usually the wood of trees; some feed on roots. Adults attack moribund, recently dead, or decomposing woody plants. They are well adapted to locate suitable host trees, particularly if they respond to volatile compounds produced by dying or recently dead trees. The conditions of the substratum (nutrient content, humidity, temperature) are of great importance in deciding whether there will be infestation or not. The adult beetles also feed on a variety of plant substrates, such as flowers, bark, foliage, fruit, roots and fungi or some may not feed at all. Upon emergence from the larval host plant, some adults undergo a period of obligatory maturation feeding, which may do considerable damage to living trees (e.g. Serixia longicornis, personal observation). With the exception of flower feeders, copulation usually occurs at the emergence site or on new host material. After copulation, males of many species remain with females as they search for and prepare oviposition sites, repeating copulation and fending off rival males.

The adults of Buprestidae are flattened, compact, usually rather large, often splendidly-coloured beetles with a metallic lustre. Due to the large size and brilliant colours of the adults, they are frequently collected and the family has been a favorite of collectors for many years. The adults are exceedingly active on the wing. A few species attack and kill apparently healthy trees; most, however, attack weakened, dead, or recently felled trees. The eggs are generally laid singly or in masses on the bark surface, under scales, or in crevices or other bark irregularities; wound edges are favoured sites. Another group of buprestids has a different mode of life; these are the stem and leaf miners (e.g. many Aphanisticus, Endelus, and Trachys species). The degree of host specificity appears to vary considerably, wood boring species tending to have wider host ranges than leaf and stem mining species, which confine their attacks to a single genus or family of plant. In those species that occur in woody plants, the phloem and xylem of the weakened trees only remain suitable for larval development for a relatively narrow time window when the trees are in a suitably weak condition to support colonisation and larval development. Apparently the females are able to detect those trees that are suitably weakened by drought, repeated defoliation, infection by pathogens, unsuitable sites for healthy growth, etc.

While it has been generally agreed that many saproxylic beetles are specialised to exploit a particular host tree, the question of proportion of specialisation is still subject to much discussion. Recent studies and reviews (Novotny et al., 2002; Basset et al., 2003) have shown that the proportion of highly specialised phytophagous beetles in the tropics is not as high as the $13.5 \%$ originally estimated by Erwin (1982). The cause of lower host specificity in the tropics might be due to the somewhat random distribution and rarity of many plants in the rain forest, which renders the search process required by a specialist too drawn out to be time- and energy-efficient. In addition to this, there is also a greater number of taxonomically related host plant species in tropical forest, favouring evolutionary switches between hosts, compared with the plant communities of higher latitudes (Novotny et al., 2002). 


\section{Methodology}

\section{Sampling method}

The main sampling and collection method was to use the traditional approach of visual collecting and sweeping vegetation with an entomological net, which has the advantage of being target-specific. Saproxylic fauna must generally be caught by hand; they seldom come to light or fly actively. The decision to use visual collecting and sweeping vegetation was also driven by efficiency as these methods do not need to deal with large numbers of common species, a major cost of processing mass samples. Coddington et al. (1991) argued that "hit and run" sampling trips are the only practical way to sample tropical biodiversity ("looking up", "looking down", beating, and sifting) due to the tremendous diversity found in tropical communities. They showed that the following modified forms of traditional collecting methods can yield analytically tractable data.

\section{Hand search + Beating (Day)}

The method involves the observer first locating suitably weakened vegetation or dead wood along or near transects. Having located a target tree, the observer starts with a visual inspection of the trunk and main branches, taking care to not touch the branches because even a small knock-on-wood can result in many specimens falling to the ground. In the case of fallen trees, special attention is paid to the underside of the trunk and branches, as this is where most species will hide during the day, and those insects spotted in this way are collected. After this initial (as hands-off as possible) inspection and collection, the observer proceeds to the beating phase, first thinking out a plan of attack, locating the branches that look the most promising, and beating them in order of priority. A hard hit (or double-hit) with a pole or stick on top of those branches does the job. Between two equally interesting spots close to each other, only one of them is chosen, because the shaking at the first spot will probably dislodge hidden specimens from the other spot and they will be lost. Despite this, it is worth beating those already slightly shaken branches, as a few species will not have fallen to the ground when exposed to only gentle shaking. Note that searching or beating the coarse wood litter on the ground is skipped with this sampling method.

\section{Sweeping/beating vegetation (Day).}

Some of the Cerambycid and Buprestid beetles are known to invade what seem to be healthy trees (though these trees are likely to be under stress). These two families of beetles are also found in foliage for maturation feeding or found mining within leaves. Thus sweeping or beating living trees is an important complementary method for surveying the biodiversity of cerambycid and buprestid beetles. Simply walking through a dense forest and sweeping vegetation (or beating branches) at random will give discouraging results. The best places to beat or sweep living trees and foliage are along forest paths (natural flyways), and around the periphery of open areas and gaps that are in the sun (though not in places overly exposed with little moisture). Recently dead or dying trees will be most productive. 
The time spent sampling was adopted as a measure of the sampling effort, because of its simplicity and universality, rather than counting the number of sweeps or number of beats. It was initially planned to keep the above two sampling protocols separate, regarding two hours of active beating as one unit of beating effort (not counting the time spent in locating the dead trees), and two hours of sweeping as one unit of sweeping effort. One can either carry out one protocol per trip, or have different persons execute these two methods simultaneously if manpower resources permit. Indeed, a collector with two stopwatches can use two methods in the same session, switching between methods, as long as the tally for each is kept independent. Being thus able to choose offers flexibility because the collector can thereby maximise the number of species sampled. However, implementation of the above scheme in the field proved to be difficult as an insufficient number of dead trees for all the surveys planned within the one-year period (even though the dead trees were revisited) could be located. Thus, the two protocols were eventually combined. Four hours of sampling (regardless whether by beating or sweeping) were taken to constitute one unit of sampling effort. In cases where dead trees could not be located, the amount of sweeping was adjusted so that the total sampling effort was still four hours, thereby rendering the sampling effort in all units in some sense still comparable.

The aforementioned sampling methods were carried out in the vicinity of five trails suggested by National Parks Board (NParks) within Bukit Timah Nature Reserve: Main Trail, Jungle Falls, South View, Lasia Valley and Catchment Path. As the resulting yield critically depended on tree falls and suitable microhabitats, the actual localities of sampling were not strictly alongside the transects but could be anywhere up to $100 \mathrm{~m}$ on either side of the designated trails. Each field trip usually covered one trail for about 4 hours, taking place in the mid-morning to early afternoon period. Six sampling cycles were carried out for each locality. With two or three field trips per month, the sampling spanned approximately one year. The order and frequency with which the localities were sampled were often driven by the presence of a tree fall, and tree fall events are stochastic in nature. If a particular trip yielded zero samples (in the target groups) due to poor weather, that trip was removed from consideration. Altogether three such trips were discarded.

Due to the active nature of the adopted sampling protocol, if there are different levels of expertise within the project team, the project leader should be present in all field trips to remove the bias that can be potentially introduced by the different experience of individuals. Alternatively, the inexperienced personnel in the company of experienced collectors can learn collecting techniques (i.e., become statistically indistinguishable) during a learning period so that they can undertake the sampling independently without introducing possible bias. For this project, the samplings were essentially carried out by the team leader alone.

Many methods of estimating biodiversity depend directly on patterns of relative abundance, as expressed in frequency distributions of species abundances in large samples. The accuracy and precision of these species richness estimates clearly depend on the number of octaves observed. However, this is a high price to pay as the cost of disclosing an additional octave of the species abundance distribution could 
require the collection of an additional 1,000 specimens, most species of which would have been known already from previous sampling. Since an automated collection method was not used, an obvious solution is to intentionally truncate the collection of abundant species (if these most common species can be recognised accurately). For this project, the non-parametric method of Chao (1984) was adopted, which only requires the number of species that occur in only one sample ('unique' species), and the number of species that occur in exactly two samples. Thus, recording/collecting a species was halted once three specimens of that species had been noted. This method is found to perform well on several test data sets from tropical forest (Colwell \& Coddington, 1994), especially if most of the information in the sample is concentrated in the lower frequency classes, i.e. 'short range' frequency data with a preponderance of relatively rare species. As this is the most common situation in inventories of diverse groups such as saproxylic beetles, this estimator is a suitable choice for the current data.

\section{Equipment}

One set of $5 \mathrm{~m}$ long sweep nets was used, made with metal rims (diameter $65 \mathrm{~cm}$ ), either of spring steel or thick aluminium in order to cope with the physical stresses when driven through dense foliage or when thumped into bush and tree branches.

\section{Sorting of family taxa}

The samples collected included dead, dried specimens of saproxylic beetles (Coleoptera) from the families Buprestidae, Cerambycidae, Curculionidae, Anthribidae, Tenebrionidae and Cleridae. As the focus of this study was on Buprestidae and Cerambycidae, given the limited manpower and resources (and only considering the diurnal fauna at that), specimens collected from other families will be identified for inventory purposes, and where appropriate, included for analysis elsewhere.

\section{Species rarity}

Species accumulation rates were plotted to estimate total diversity of the samples. Assessments of the rarity of particular species were more problematic. For most insect groups in many countries, there is often no documented list of nationally threatened or rare species; rather the status of the insects often depends on the judgment of the local taxonomic specialists (if available). Here it is the author who, according to his best judgment, designated the status of rarity, admittedly a concept that is complex and sometimes difficult to define with precision. In particular, species while not necessarily rare or uncommon, are nevertheless quite random in occurrence in tropical forest (see discussion in the section on "Beetle assemblage"). In this paper the author uses pockets of population (i.e., number of known locations) and frequency of encounters in the author's past 20 years of entomological field work as a guide. 


\section{Results}

Almost all cerambycid and buprestid specimens were identified to genus level. Identification to specific level depends upon further examination and processing but might not be possible for some of the specimens in the short term, either pending the taxonomic revision of a whole genus, or due to the poor knowledge of local fauna and the possibilities of new undescribed species. Many groups in Cerambycidae (e.g. the genus Pterolophia, and the genus Egesina, shown in Fig. 1) and Buprestidae (e.g. the genus Agrilus, some examples of which are shown in Fig. 2-4) are impossible to identify without studying the types in overseas museums. Morpho-species (consistently recognisable units) identification should be achievable for the majority of specimens in the groups chosen, except for some notoriously difficult groups such as Agrilus in the family Buprestidae, where there remain some doubts even at the morpho-species level.

\section{Total diversity}

The lists of species provided in Tables 1 and 2 give an outline of the gathered species diversity. There were 38 cerambycids and 15 buprestids in total. Table 3 summarises the total number of species observed and their relative abundance. The last column of Table 3 shows the species richness estimator $S$ computed using the non-parametric Chao estimator (actually the lower bound) mentioned in the preceding section:

$$
S=S_{o b s}+\left(L^{2} / 2 M\right)
$$

where $S_{o b s}$ is the observed number of species in a sample, $L$ is the number of species that occur in only one sample ('unique' species, "singletons"), and $M$ is the number of species that occur in exactly two samples ("doubletons").

The species accumulation curves for both the cerambycids and buprestids are plotted in Fig. 5. As can be seen from the figure, the species accumulation curves of both families showed a somewhat slower rate of increase over time, but there is no evidence that they reached a plateau within the survey period of one year. Indeed, given that it has been argued (Janzen, 1988) that it takes five to ten years to characterise the insect faunas of several tree species in a tropical forest, the present survey results are not unexpected. The two bottom curves show the accumulation of species considered to be 'rare' in Cerambycidae and Buprestidae. It can be seen that in this one year of study, c. $75 \%$ of the species that were found are common species. Accumulation of rare saproxylic species can be very slow, and it would probably take more years of study to reveal the pattern of increase.

Among the beetle species considered rare, several are new records for Singapore with respect to personal checklists maintained by the author. For cerambycids, they are $\# 1,9,13,20,21$, and 23 in Table 1. For buprestids, it is difficult to give a definite list of new records to Singapore at this time, due to the taxonomic difficulties with species in the genera Agrilus and Trachys (including the subgenus Habroloma) (see Fig. 6). 


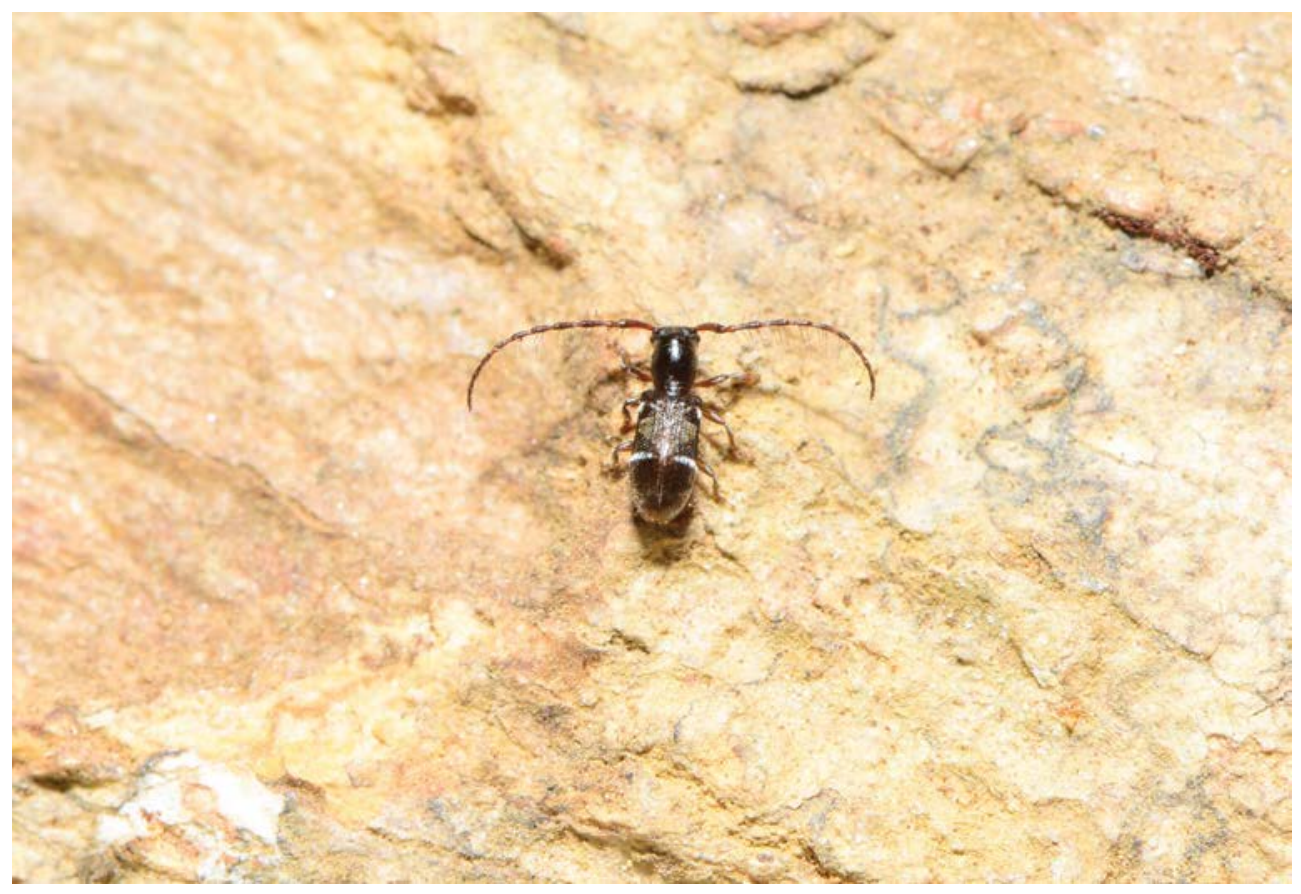

Fig. 1. Egesina sp. (Cerambycidae) (Photo: L.F. Cheong)

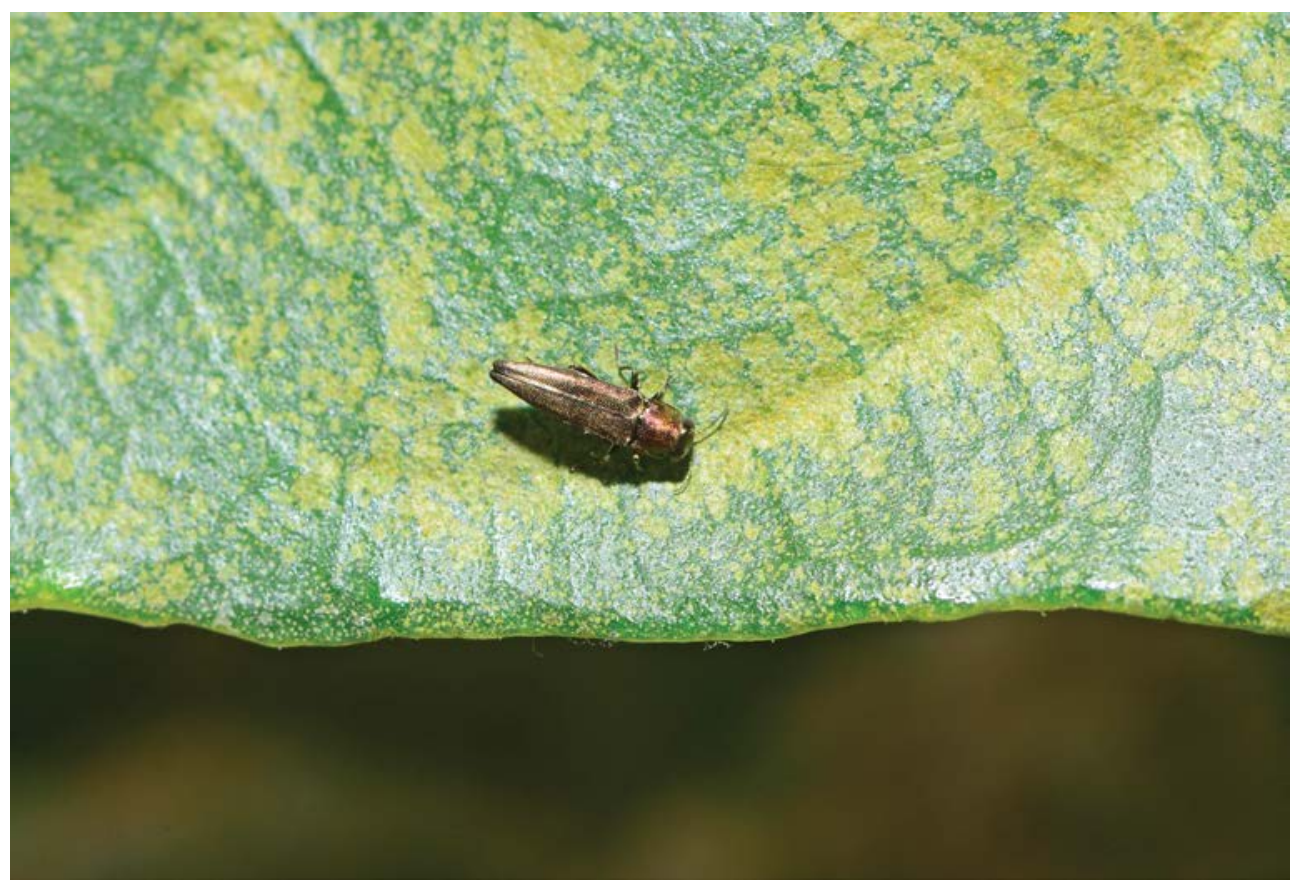

Fig. 2. Agrilus cf. fidelis sp. 1 (Buprestidae) (Photo: L.F. Cheong) 


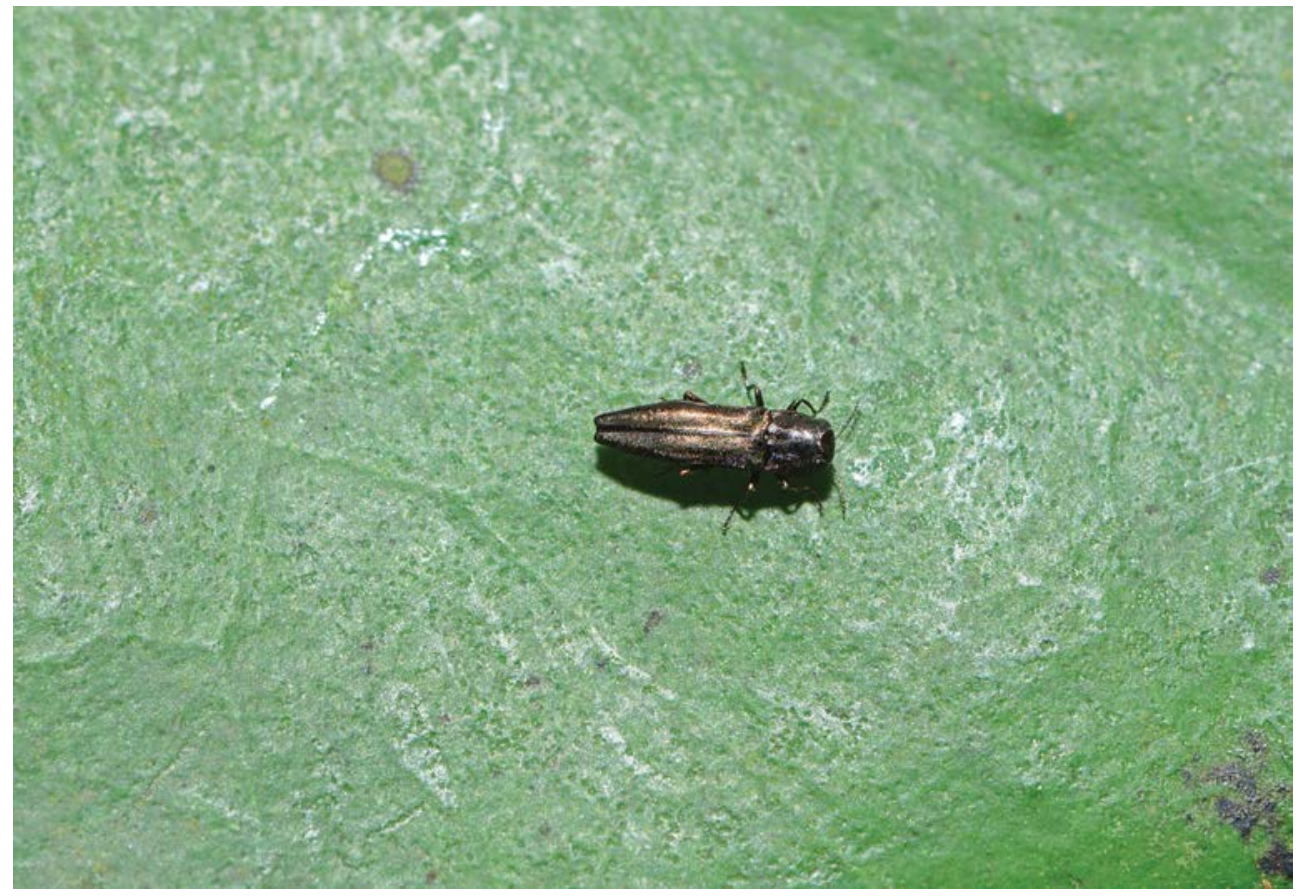

Fig. 3. Agrilus cf. fidelis sp. 2 (Buprestidae) (Photo: L.F. Cheong)

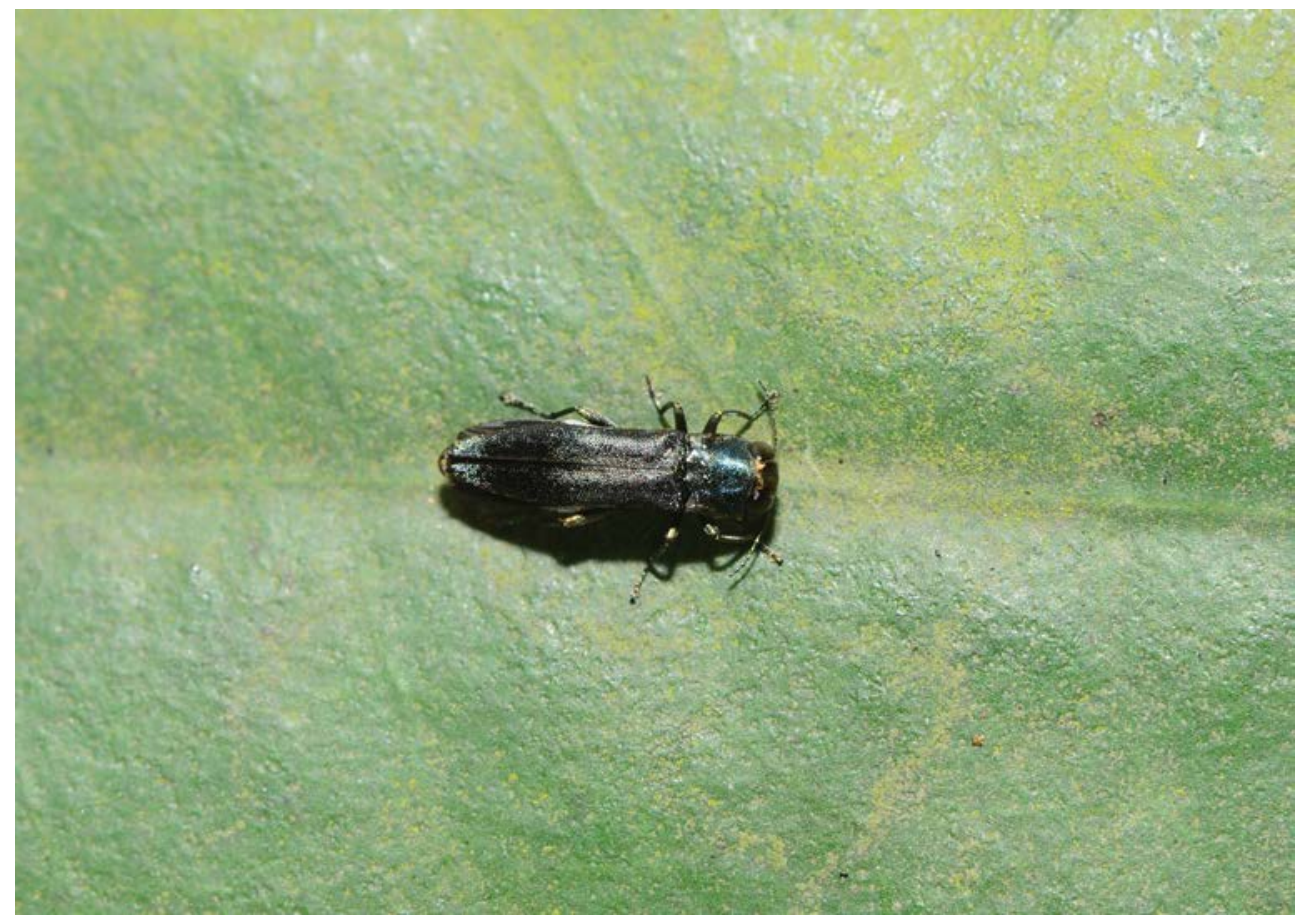

Fig. 4. Agrilus tripartitus (Buprestidae) (Photo: L.F. Cheong) 
Table 1. Cerambycid beetle species collected from the survey of Bukit Timah Nature Reserve, Singapore.

Abbreviations: *: singleton; **: doubleton

\section{\# $\quad$ Species}

1. Acrocyrta cf clytoides *

2. Apomecyna sp. cf naevia*

3. Cacia confusa *

4. Chloridolum thomsoni *

5. Cleptometopus terrestris **

6. Daxata ustulata **

7. Demonax mulio *

8. Dialeges pauper *

9. Diamecyna cf setifera *

10. Driopea clytina **

11. Egesina minuta **

12. Egesina rigida

13. Egesina $\mathrm{sp} *$

14. Exocentrus moerens *

15. Glenea saperdoides **

16. Menesia pulchella **

17. Myagrus vinosus*

18. Sybra singaporensis *

19. Nedine adversa

20. Neosybra cylindrica or Neosybra rotundipennis *

21. Notomulciber cf sexlineatus *

22. Nyctimenius tristis

23. Pharsalia supposita*

24. Polyphida modesta*

25. Pothyne cf griseolineata *

26. Pterolophia humeralis

27. Pterolophia illicita

28. Pterolophia crassipes

29. Ropica angusticollis **

30. Sclethrus malayanus *

31. Serixia longicornis ** 
Table1. Continuation.

\# $\quad$ Species

32. Serixia prolata *

33. Sybra arator

34. Sybra fervida or S. cretifera

35. Tetraommatus testaceus *

36. Xenolea tomentosa

37. Xylotrechus buqueti

38. Xylotrechus javanicus

Table 2. Buprestid beetle species collected from the survey of Bukit Timah Nature Reserve, Singapore.

Abbreviations: *: singleton; **: doubleton

\section{\# $\quad$ Species}

1. Agrilus $\mathrm{cf}$ fidelis sp. 1 (red prothorax) *

2. Agrilus cf insularis *

3. Agrilus cf tripartitus *

4. $\quad$ Agrilus lazar $=A$. cf. lazar (golden clypeus) $^{+}$

5. Agrilus sp. 1 (golden fron)

6. Agrilus sp. cf fidelis sp. 2 (black)*

7. Chrysobothris sp. (uncollected) *

8. Chrysobothris superba

9. $\quad$ Endelus cupido

10. Endelus nitidus **

11. Trachys (Habroloma) cf aeneolum sp. $1=$ sp. $2^{* *+}$

12. Trachys (Habroloma) cf andromache *

13. Trachys (Habroloma) cf congener *

14. Trachys (Habroloma) lepidoptera

15. Melobasis trifasciata *

${ }^{+}$Despite some morphological differences possibly due to sexual dimorphism, I have treated Agrilus cf lazar (golden clypeus) as the male of Agrilus lazar, and Habroloma aeneolum sp1=Habroloma aeneolum sp. 2. 
Table 3. Number of saproxylic beetle species observed in Bukit Timah Nature Reserve, their relative abundance, and estimated species richness. $S_{o b s}$ is the observed number of species, $L$ the number of singletons, $M$ the number of doubletons, and $\mathrm{S}$ the estimated species richness.

\begin{tabular}{lcccc}
\hline & $\boldsymbol{S}_{\text {obs }}$ & $\boldsymbol{L}$ & $\boldsymbol{M}$ & $\boldsymbol{S}$ \\
\hline Cerambycidae & 38 & 19 & 8 & 61 \\
Buprestidae & 15 & 8 & 2 & 31 \\
\hline
\end{tabular}

For instance, \#1, 3, 5, and 6 in Table 2 are possibly Agrilus species new to Singapore but these can only be ascertained after detailed examination by experts. Collection of possibly six (out of 38) cerambycids and possibly four (out of 15) buprestids that may be new records for Singapore suggests the potential for more discoveries.

\section{Availability of microhabitats along transects}

Table 4 presents the number of species collected along the different transects within Bukit Timah Nature Reserve. Ubiquitous species (occurring in three or more transects) include Sybra arator, Sybra fervida or S. cretifera, Egesina rigida, Pterolophia humeralis, Agrilus sp. 1 (golden frons). In actual fact, many species in the list are quite widespread; more sampling would certainly produce more "ubiquitous" species. It should also be noted that some rather common buprestid species, such as Agrilus purpurifrons and $A$. raapi, both of which can be found on dead trees, have not been recorded from this year of survey. This again attests to the fact that even common species can have rather random occurrence in tropical forest and to the need for a longer period of sampling.

That the Main trail (Main), Jungle Fall (JF) and Southview (SV) transects rank highest in terms of number of cerambycid species by the end of the survey may or may not be indicative of the diversity of these habitats; it could be simply due to the fact that it is on these trails that dead trees of significant girth happened to be found. In particular,

- Main trail (two dead trees, respectively at Simpang hut and Catchment trail junction): 16 cerambycid species, with one rare species

- Jungle Fall (three dead trees, respectively at junction with main trail, near bottom of stairway, and towards the Dairy Farm sector): 12 cerambycid species, with five of them rare. The significant arboreal deadwood present in the dead trees found yielded a high number of rare species. Though not belonging to Cerambycidae or Buprestidae, it should also be noted that two rare Cleridae were obtained at one of these dead trees: Teneropsis cf. sumatrense (Fig. 7) and a Tenerus species 


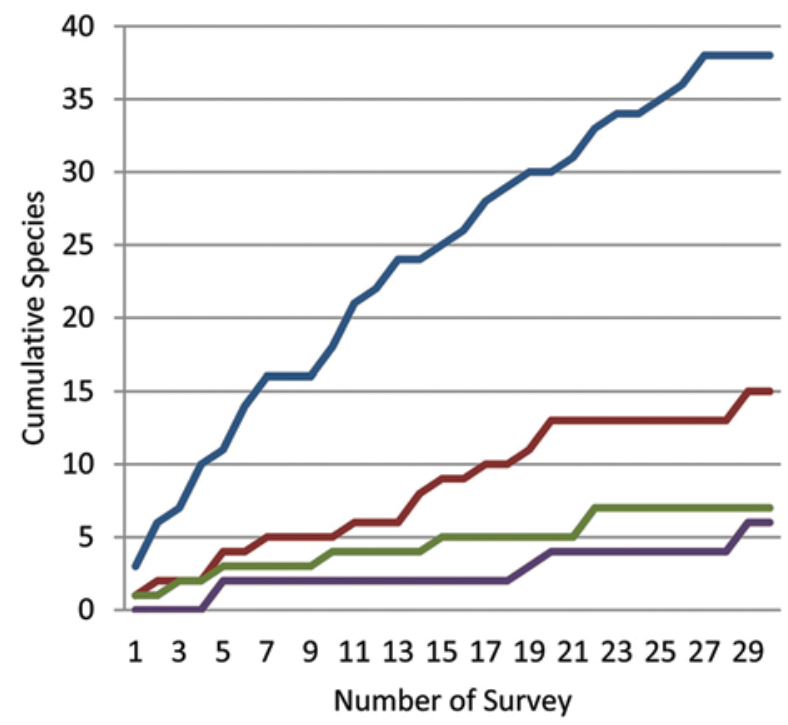

Cumulative species of Cerambycid

Cumulative species of Buprestid

Cumulative rare Cerambycid

Cumulative Rare Buprestid

Cumulative species of Cerambycid

Cumulative species of Buprestid

Cumulative rare Cerambycid

Fig 5. Species accumulation curves for Bupestrid and Cerambycid beetles.

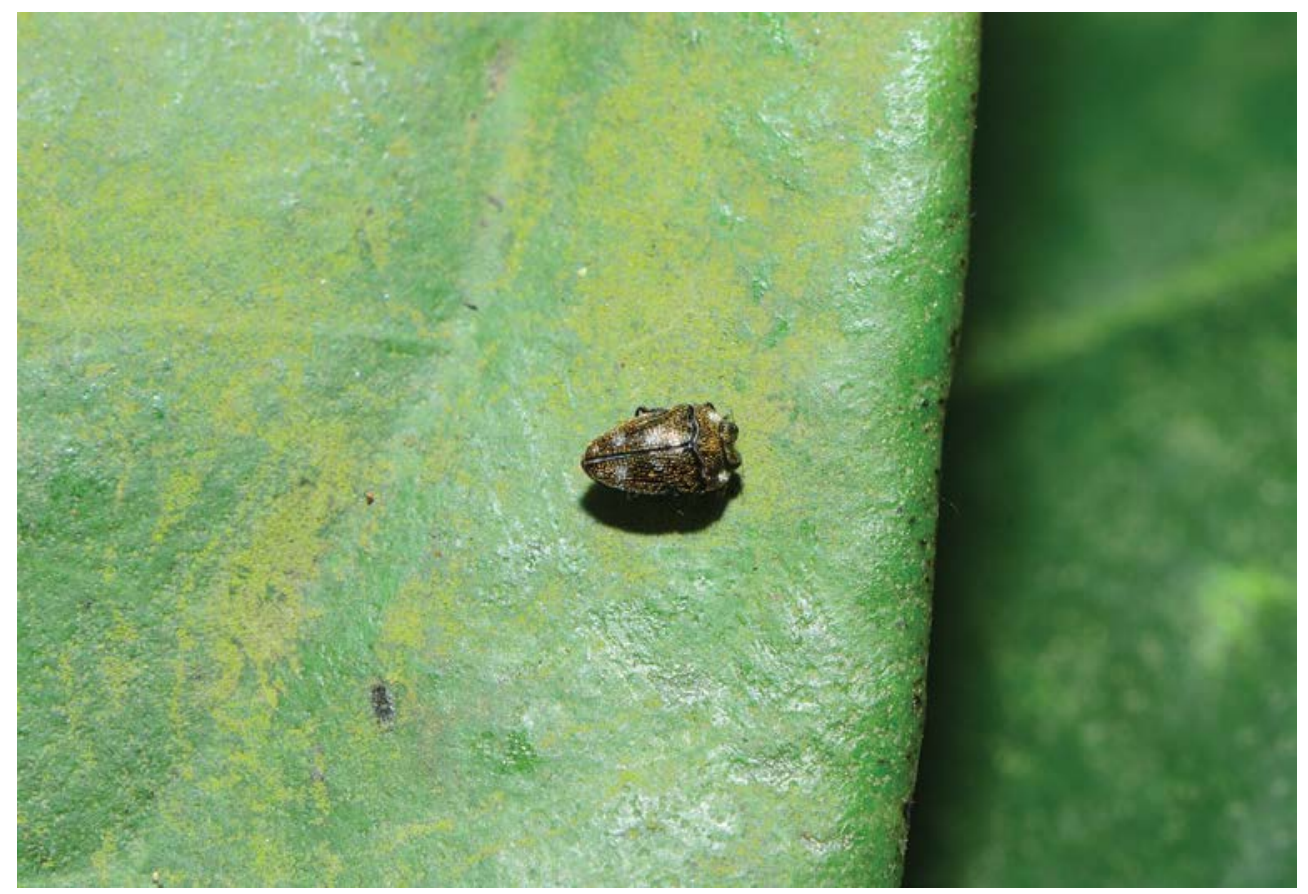

Fig. 6. Trachys (Habroloma) cf. aeneolum sp. 2 (Buprestidae) (Photo: L.F. Cheong) 
Table 4. Cumulative number of saproxylic beetle species observed at each transect within Bukit Timah Nature Reserve, Singapore.

\begin{tabular}{|c|c|c|c|c|c|c|c|c|c|c|}
\hline \multirow{2}{*}{$\begin{array}{l}\text { No. of surveys } \\
\text { conducted }\end{array}$} & \multicolumn{5}{|c|}{ Cerambycidae } & \multicolumn{5}{|c|}{ Buprestidae } \\
\hline & 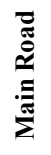 & 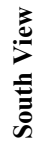 & 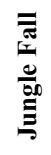 & 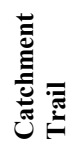 & 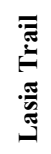 & 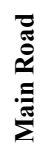 & 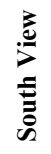 & 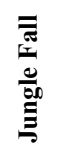 & 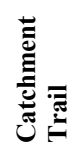 & 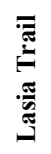 \\
\hline 1 & 3 & 3 & 3 & 1 & 5 & 0 & 0 & 1 & 0 & 1 \\
\hline 2 & 6 & 6 & 6 & 3 & 5 & 0 & 0 & 2 & 1 & 3 \\
\hline 3 & 10 & 8 & 7 & 4 & 6 & 1 & 2 & 2 & 2 & 3 \\
\hline 4 & 12 & 9 & 8 & 5 & 7 & 1 & 2 & 4 & 4 & 4 \\
\hline 5 & 15 & 13 & 10 & 6 & 8 & 2 & 2 & 4 & 6 & 4 \\
\hline 6 & 16 & 13 & 12 & 6 & 8 & 2 & 2 & 4 & 7 & 4 \\
\hline
\end{tabular}

- Southview (one small dead tree and two dead trees not freshly fallen): while this transect ranks second highest in terms of the number of cerambycid species (13), none are rare species, given the non-optimal conditions of the dead trees found

For buprestids, many species attack living but weakened or stressed trees. While the insects are able to detect such suitable trees, the human surveyor has to rely on his experience, since the weakened or stressed trees may not have visible physical signs and often many Buprestids (in particular, the numerous Agrilus species) are swept from the foliage of apparently healthy trees. Generally speaking, there is often a richer diversity of Buprestid beetle species near habitat where the moisture in the environment is better retained. These could be areas near streams, enclosed valley with trapped moisture (preserving the humid, shaded forest interior conditions that are mostly gone from Bukit Timah). The presence of streams also creates a heterogeneous habitat, allowing diverse microenvironments to exist. This could be the reason why the Jungle Fall, Catchment and Lasia transects have higher number of buprestid species collected. Note that for the case of Lasia valley, a rare Tiger Beetle, Protocollyris sp., was obtained. The stream at Jungle Fall trail (the one nearer to Dairy Farm) could be interesting as well, if not for the dense rattan which presents difficulties for traversing and sweeping. In contrast, the habitat along the main trail seems to present the least amount of moist and cool areas; this might account for its low buprestid diversity. Similar factors would affect other beetle families, such as the Attelabidae (Fig. 8).

Due to the considerable heterogeneity of tropical forests (compared to temperate forests), it has been suggested (Condit, 1996) that a representative study site for tropical woody plants should be at least 50 ha. The same area would probably be needed when phytophagous or saproxylic insects are considered. Thus it would be 
more meaningful to consider the species collected from the various transects of Bukit Timah as a whole, which is the focus of discussion below.

\section{Discussion}

\section{Species richness and decline}

Are the total species richness estimates in Table 3 an accurate reflection of the local species richness for these two families (even allowing for the intentional omission of nocturnal species, species in tree hollows, species in veteris (Highly Decomposed) wood, and species better collected by other methods)? It is uncertain, as there is no theoretical or empirical estimate of the number of cerambycid or buprestid species at any similar particular tropical forest site (however that site is defined) using similar protocol. However, the historical data are available from the species collected by A.R. Wallace in his eight-year sojourn of the Malay Archipelago from 1854 to 1862 (Deyrolle, 1864; Pascoe, 1864-1869), which is part of the reason for focusing on these two families of beetles.

\section{Cerambycids}

Wallace stayed in Singapore for about two months and collected 133 cerambycid species (Pascoe, 1864-1869: see Appendix 1 for the species list) (some of the original 136 listed species have been merged because they are merely sexes of one species). Given the many potential differences in the respective collecting methods, it is impossible to draw firm conclusions from comparing the present data with the historical data. For instance, Wallace might have employed multiple collectors; his collecting effort also had the convenience of the various sawmill and logging activities near the foot of Bukit Timah, which Wallace considered to act as an efficient trap for saproxylic beetles. Having said that, there are also broad similarities between the two collections. Firstly, assuming that there had been intensive collecting efforts by Wallace (given that he was on an expedition financed by the sale of specimens collected), then allowing for 50\% downtime due to weather and logistical issues, then the resulting 30 days of collecting are roughly equivalent to the 30 sample points in this survey. Another similarity lies in the largely diurnal fauna that made up the two sets of collections. While it is not clearly stated in the historical literature if Wallace collected only in the daytime (as was done in the current survey), it is likely to be the case given that the nocturnal cerambycid fauna is quite poorly represented in his collection (e.g. only one Ceresium species, no Coptops, Palimna, Pothyne, nor even the common Anancylus (Paranancylus) griseatus). For some rather speciose genera such as Sybra and Chloridolum, only the diurnal Sybra arator, Chloridolum thomsoni and $C$. ceycinum were collected.

With the preceding remarks in mind, some broad observations can be made about the comparison. Firstly, only 38 cerambycid species were collected, compared to Wallace's 133. Even the current estimated total of 61 species is a far cry from 133. Thus, either there has been a sharp decline in the cerambycid diversity, or the present 


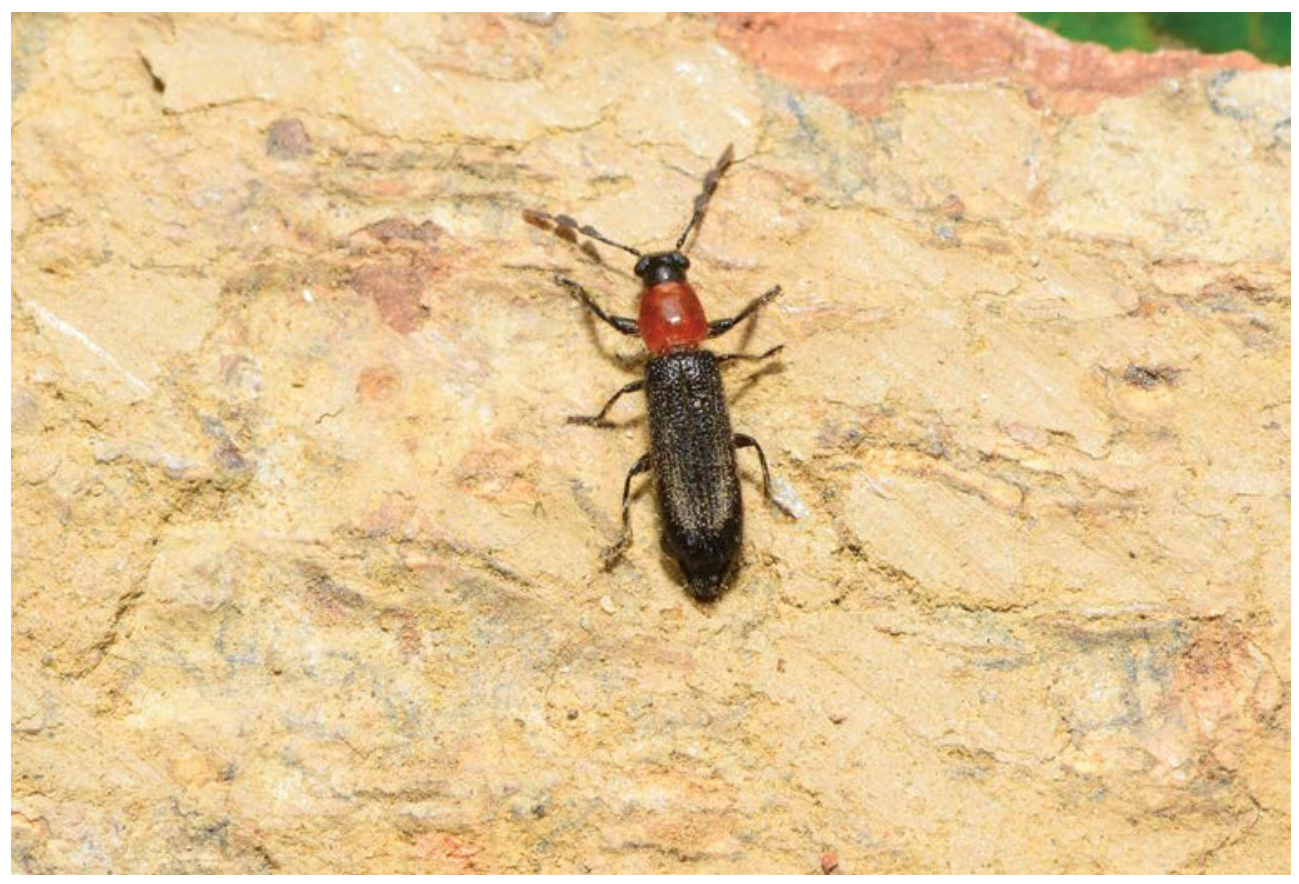

Fig. 7. Teneropsis cf. sumatrense (Cleridae) (Photo: L.F. Cheong)

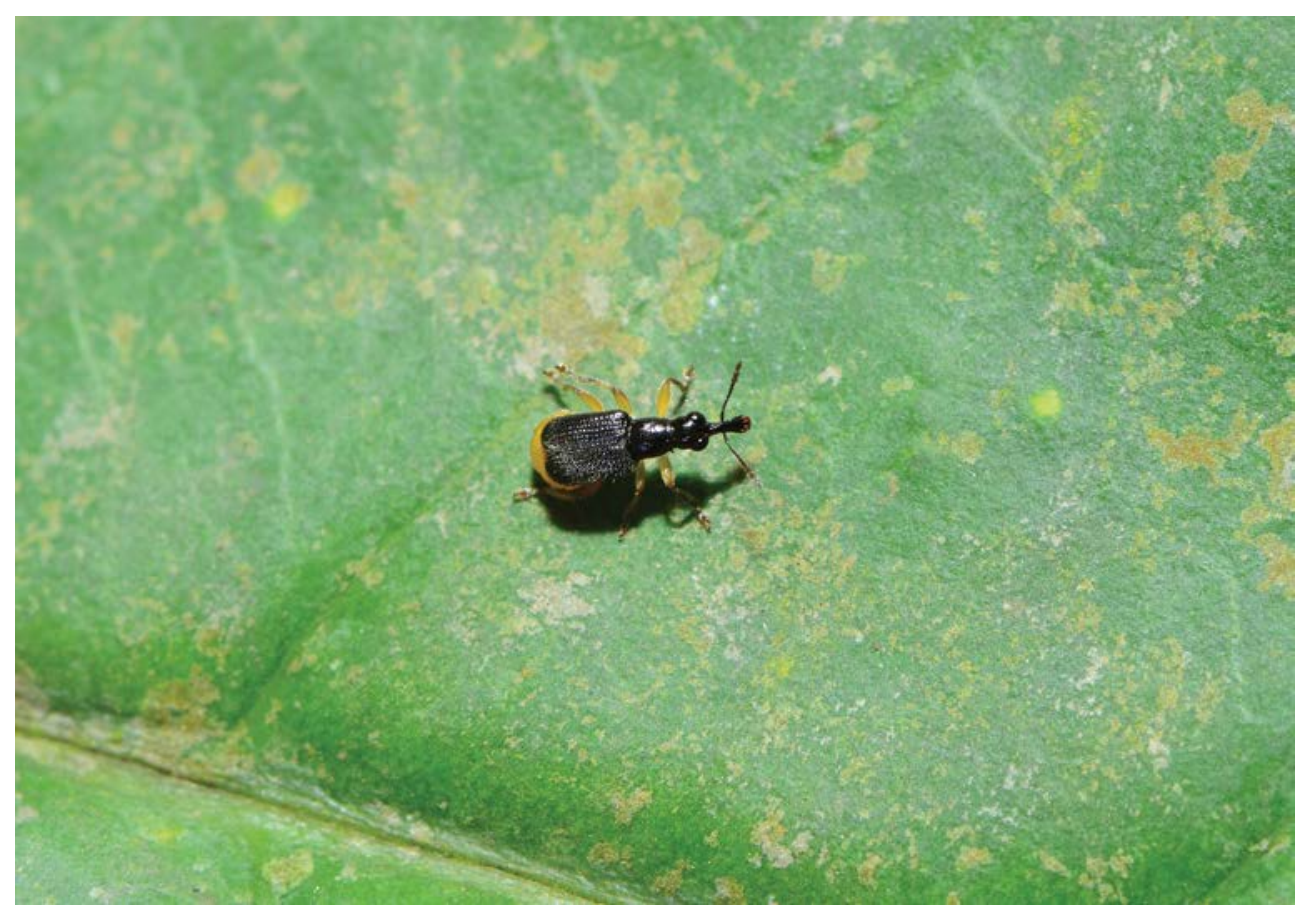

Fig. 8. Deporaus sp. (Attelabidae) (Photo: L.F. Cheong) 
sampling intensity has not been adequate to arrive at a good total species estimate. The former is more likely for the following reasons. Firstly, the non-parametric Chao estimator is known to perform well for even small numbers of sampling. Furthermore, it is most revealing that almost none of the speciose diurnal genera such as Glenea, Oberea, and Demonax were collected in the present sampling (only one Glenea species collected), compared with their rich presence in Wallace's collection. Given their colourful and eye-catching appearance, it is unlikely that so many of them would have been missed by the author if present (one can also reach a similar conclusion by comparing the frequency of Glenea encountered in lowland Malaysian forests or, to a much lesser extent, in other larger forest sites like Nee Soon freshwater swamp forest in Singapore). Lastly, many parts of the forest have relatively low humidity levels, due to the lack of a buffer between Bukit Timah and the surrounding drying environment, the criss-crossing of trails, and the increasing number of canopy gaps. As mentioned above, Bukit Timah has lost much of its humid, shaded forest interior habitat; longtime observers of the forest also believe that the upper storey of the forest is thinning out and not being replaced (Corlett, 1995). No doubt many insect species requiring such forest conditions and large trees are also gone.

\section{Buprestids.}

Deyrolle (1864) described 355 buprestid species collected by A.R. Wallace from the Malay Archipelago. Of these, there are 22 specimens with Singapore as type locality (with 12 from the hyperdiverse genus Agrilus) (see Appendix 2 for the species list). It might be possible that some other common species were present in Singapore and collected by Wallace then, but they were not explicitly reported by Deyrolle because the types were described from other localities. This is suspected to be the case for some of the common species such as Agrilus purpurifrons, A. raapi, Endelus empyreus and E. nitidus. The material subsequently collected by C.F. Baker and $\mathrm{J}$. Baum at around the turn of the 20th century significantly added to the buprestid species list of Singapore (Obenberger, 1924, 1929a, 1929b), especially the smaller buprestid species such as those from the genus Trachys. However, Baker might have had a prolonged stay in Singapore (he joined the staff of Singapore Botanic Gardens in 1917 and acted as Assistant Director for a period), affording him a longer period for collection. And it is also not clear where he collected. Due to the difficulty in interpreting Baker's and Baum's material, only Wallace's material has been used here for analysis. First, only 15 species were collected compared to Wallace's 22. It should be noted that Wallace's material seems to comprise mainly the larger species; perhaps the collectors did not pay attention to the smaller species such as those belonging to the genera Trachys and Endelus. On the other hand, the current collection is almost devoid of the large buprestid fauna, but the smaller species are well represented and the total number of species has been significantly enhanced by the latter's presence. Even then, the current collected total of 15 species from the survey is still somewhat less than the 22 of Wallace. Of the 22 species collected by Wallace, only three species were recorded in this survey. In particular, of the 12 Agrilus species collected by Wallace, only Agrilus insularis is still present; i.e., 11 of them were not recorded in this survey, 
and in fact have not been recorded in Singapore since Wallace's time. No doubt, part of the reason is the aforementioned exaggerated complementarity, so that the lack of overlap may not be indicative of true absence. Nevertheless, it is indicative that in a two-month period, Wallace collected 12 Agrilus species, and of these, 11 have not been recorded by the author in the whole of Singapore despite efforts spanning two decades.

The beetle genus Agrilus is by far the largest genus of the family Buprestidae with 2784 species cited by Bellamy (2008). In fact, as presently defined, Agrilus appears to be the most speciose conventionally accepted genus in the entire animal kingdom. Difficulties in Agrilus identification include: hundreds of new species remain to be discovered and described, type specimens of older names are scattered in various collections, often with primary types not designated, and apparently hundreds of synonyms remain undetected. Due to these difficulties, hardly any world region has its Agrilus fauna adequately revised. In Malaysia alone, there are 139 valid taxa known so far, whereas the estimated real number is at least 500 (E. Jendek, pers. comm., 1 Nov. 2013).

\section{Beetle assemblage}

The almost random occurrence of beetles due to small sample sizes was mentioned above. In fact, even when the samples are reasonably large, the beetle fauna in the tropical rain forest can be still characterised by an almost random distribution of species each with a low population level (Floren \& Linsenmair, 1998), unlike the beetle fauna of temperate forest. Furthermore, the more undisturbed the forest is, the more variable and unpredictable the composition is. This stands in contrast to the disturbed areas, whereby the beetle assemblage is much more predictable and less diverse.

The results of the current survey, as well as from the author's past personal observation, show that the early secondary forest zone (such as the Lasia area and part of the Catchment path) has the most predictable beetle assemblage. Species like Menesia pulchella, and Nyctimenius tristis can be found frequently. Individuals such as those of Xylotrechus javanicus, typically found on the forest margin, can reach high numbers. The Catchment and the Jungle Fall areas contain primary vegetation; thus they also harbour the more interesting fauna, especially in the interior areas near streams or enclosed by valleys that better preserve moisture. This type of beetle fauna, while not necessarily rare or uncommon, is nevertheless quite random in occurrence. Examples include Polyphida modesta, Chloridolum thomsoni, Serixia longicornis, many of the Agrilus species. However, the irregular shape of the primary forest zone, the presence of wide paths, and the exposed slope all mean that they are also subject to the influence of the disturbed external environment. Thus, the beetle assemblage is also marked by the occurrence of frequent species (e.g. Egesina minuta, Nedine adversa, and Sybra arator) that are usually found at the forest edge, especially in samples collected near the trails. This is quite unlike the beetle assemblage reported in the literature from large areas of pristine primary forest, where frequent species were never observed (Floren \& Linsenmair, 2003). As was found by Floren \& 
Linsenmair (2003), anthropogenic disturbances could have long lasting effects on beetle assemblage structure, even after decades of forest regeneration. For the Catchment and the Jungle Fall regions, past disturbances have led to the occurrence of common tree species in these parts of the forest, and also brought about changes to the abiotic conditions (see Chatterjea, 2019) due to the aforementioned fragmentation. Either or both of these factors could lead to the occurrence of common species in these transects.

\section{Differences between forest types}

An aim of the 2015-2016 biological survey of Bukit Timah Nature Reserve was to assess floristic and faunistic differences between the primary and secondary forest. This was a reason for suggesting the Main Trail, Jungle Falls, South View, Lasia Valley and Catchment Path as specific study locations within the nature reserve.

While in principle the species complementarity along different trails within Bukit Timah can be computed, this is not very meaningful for saproxylic beetles, for the following reasons. Firstly, the occurrence of the saproxylic beetles is dependent on the microhabitat of the treefall (the tree species (primary/secondary), tree diameter, degree of decay, level of sun exposure/canopy closure, whether the dead tree is standing or lying, the species of wood decaying fungi colonising the wood etc.). Every treefall is different. While the occurrence of saproxylic beetles is therefore affected by vegetation type, the survey transects are not located within a large forest continuum represented by the same vegetation type. Rather, it is a patchwork of heterogeneous habitat, with areas of primary and secondary vegetation in close proximity. For instance, the Lasia valley habitat consists of maturing secondary and old secondary vegetation, and this is no more than $100 \mathrm{~m}$ away from primary vegetation. In fact, nowhere in the reserve is more than $200 \mathrm{~m}$ from a forest margin. Given that many saproxylic beetles are somewhat mobile in order to search for dead trees, to expect certain species to be diagnostic of the forest type would be to mask the dynamic aspect, as well as the non-homogeneous nature of the vegetation surrounding the transects. Another reason is that the complementarity of two transects will be overestimated if inventories for either or both transects are incomplete. Given that many buprestids and cerambycids are to some extent tree specialists, large samples of weakened trees would be needed that are representative of all sites. This condition is difficult to meet in a one-year survey. The type of deadwood encountered in each transect is simply not diverse enough, which will exaggerate the level of complementarity. For instance, for the twelve and six cerambycid species collected along the Jungle Fall and the Catchment transects respectively, there is only one species common to both transects. There is no doubt that the real complementarity should be much lower, given the similar vegetation along both transects, and the fact that many species in the above lists are common and widespread species.

If the aim is to compare the occurrence of rare species in different areas or habitats, the requirements are even more stringent. The occurrence of rare and threatened species in small samples is almost random and comparisons among forests are likely to produce unreliable rankings if based only on such data collected from 
short duration. The rarity of beetle species in highly diverse tropical forest has been discussed above in the section on the beetle assemblage.

\section{Reflections on protocol and recommendations}

A protocol based on dead wood beating has its limitations. It depends on the sporadic occurrence of fallen trees, and it also depends on the ability to find those trees within the two to three week time window following treefall that has the highest yield of saproxylic beetles. This results in a low number of suitable dead trees that are actually encountered in their optimal states in the survey.

While sweeping can be done seemingly anywhere, independent of the chance occurrence of treefalls, sweeping needs familiarity and experience with the microhabitat (knowing where to sweep) to obtain optimal yield. It lacks constancy of yield if not performed in the right habitats, becoming much more dependent on chance occurrence of beetles in those habitats sampled. Even in the right habitats, the element of chance is still much more pronounced compared to the more targeted protocol of beating.

If manpower resource and time (i.e. a longer survey period) permit, it might be better to separate the beating and the sweeping, or to have different persons executing these two methods simultaneously. This is to allow the individual method to be executed under optimal conditions (e.g. less fatigue, best time of the day, especially pertinent in the monsoon period when there is often rain onset in the early afternoon). A longer survey period will also even out some of the randomness inherent in the occurrence of saproxylic beetles.

Future study might also consider window flight traps, which could efficiently and passively capture saproxylic Coleoptera flying inside the forest, especially around tree trunks (Ranius \& Jansson, 2002), providing more information on species richness and composition.

\section{Management recommendations}

Tree mortality has a fairly large random component in space and time. This implies that species dependent on dead wood must track the availability of a fairly unpredictable habitat. Therefore, wood dependent species must compensate for local extinction with new colonisations through dispersal and establishment on newly dead trees. Dispersal distances vary greatly, depending on the longevity of the deadwood habitat used (e.g. bracket fungi are more long-lasting). For species with more limited dispersal capability, survival in fragmented landscapes depends on their ability to persist without a "mainland" source. The fragmentary nature of Bukit Timah means that it is probably too small for the full fauna to be maintained in the long run by chance "disasters" providing continuity of available tree falls and natural patches. Furthermore, with the loss of over-mature old trees, dead-wood development is then restricted to the die-off of typically small diameter trees, producing less diverse dead wood. Thus, the local extinction of saproxylic insect species is probably steadily taking place, as shown by the preceding comparisons with the historical materials. 
What are some good forest management practices that can mitigate the threats faced by saproxylic insects? Firstly, common sense dictates that saproxylic species associated with dead wood will not thrive if dead wood (perhaps already containing beetle eggs or larvae) is cleared away from the forest. Unfortunately, dead trees have been selectively removed from the forest for various reasons. Secondly, dead trees should be left, as much as possible, in their original assorted conditions of standing and fallen states, subject to a range of different abiotic conditions (Fig. 9). This will increase the diversity of available dead wood microhabitats and microclimates necessary to ensure the long-term stability and preservation of the saproxylic community. However, the current practice is that trees that have fallen on or near forest trails are processed in a way that is quite detrimental to the saproxylic insects. Often, only the main trunk is kept; most of the small branches and twigs are removed. Sometimes, the major trunks and branches are sawn into small stockpiles for removal or for moving to off-trail locations. As a result, the richness of the deadwood habitat is drastically reduced. Firstly, the small branches and twigs provide suitable habitats to a large number of species (often rare and endangered ones). The big tree trunk, with the thicker outer surface, may not be penetrable to many of the smaller beetles trying to lay eggs on the dead tree. Secondly, by trimming off the branches so that the tree trunks lie flat on the ground, the overhanging surfaces - crucial for providing shade and a suitable growing environment for fungi - have been largely removed. This practice would be detrimental to many groups of saproxylic beetles that live on the shady undersides of tree trunks. It is recommended that, even when it is necessary to clear a dead tree away from the trail due to public safety considerations, one should try to move the material to the side of the trail, while at the same time trying to preserve intact, as much as possible, the structural heterogeneity of the dead trees. Wherever possible, especially when concerning big old trees that yield very rich, varied, and longstanding saproxylic resources, rerouting the trail or even closing off access to the tree with fencing or other barriers could be considered. These big old dead trees are often referred to as "habitat trees" or "keystone structures," which are particularly important as they contain slowly developing microhabitats, such as cavities (Davies et al., 2007; Lindenmayer et al., 2012). In this case, it will also be an opportunity to provide signs to explain to the public the necessity of the measures - that deadwood is an essential component of a healthy forest, as important as the living trees themselves. Once it is recognised that trees continue to fulfil their ecological function in the forest long after their death, it becomes apparent that the sight of a dying tree is not an eyesore, but a most beautiful form of death.

Besides the passive measure of retaining senescent and dead trees to maintain the availability of dead wood, one can also adopt a more deliberate, active approach to increase dead wood. For various reasons, non-native woody plants now feature prominently in many wooded areas of Singapore. This is true in the buffer area surrounding Bukit Timah too. The dying and dead wood produced by these plants represent novel resources for saproxylic insects, but their suitability to these organisms remains poorly understood. From the author's past personal observation, the Albizia tree (Falcataria moluccana (Miq.) Barneby \& J.W.Grimes) does support a high 


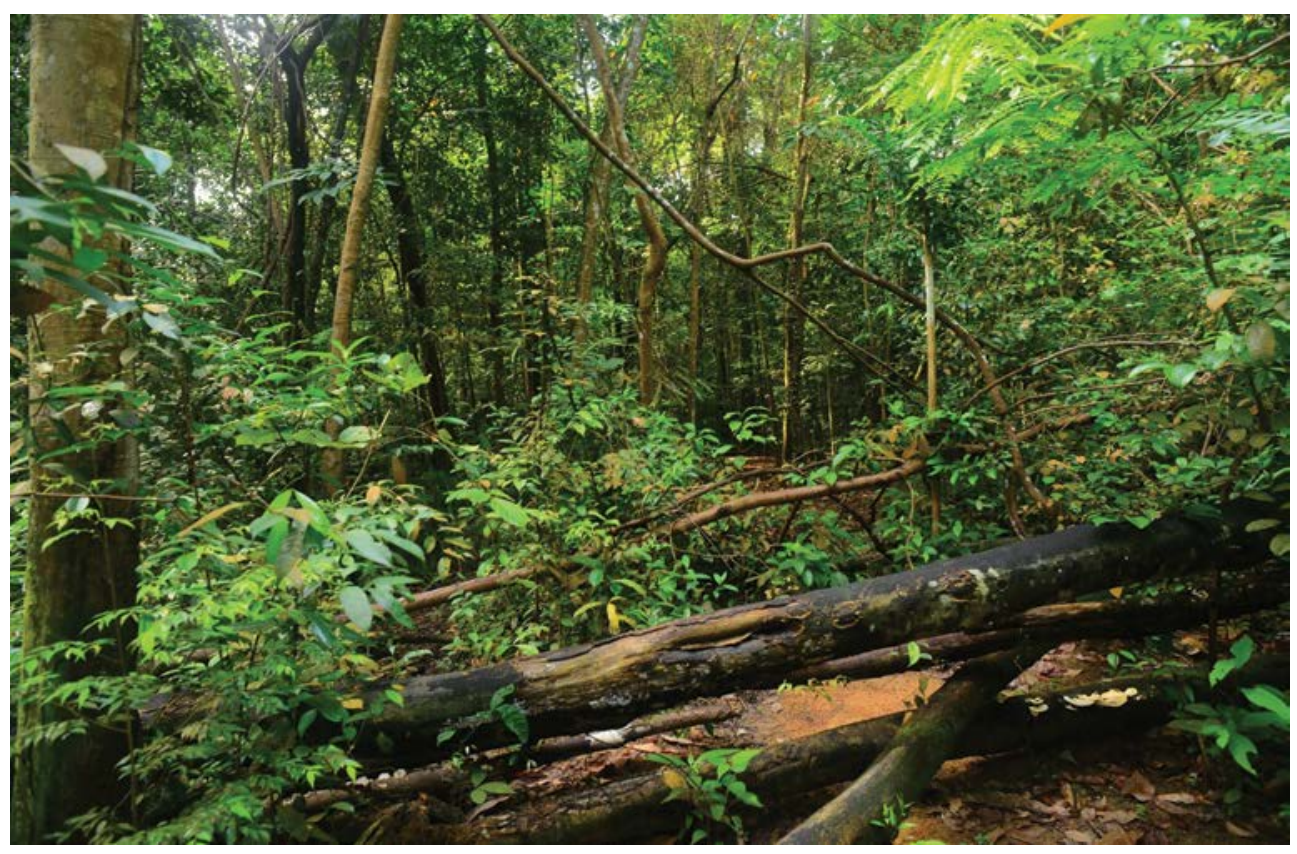

Fig. 9. Example of natural tree fall left in place, allowing for development of myriad microhabitats. (Photo: L.F. Cheong)

beetle diversity, although the beetles found are usually the common generalist species. Thus, deliberate felling of Albizia in the buffer zone surrounding Bukit Timah Nature Reserve would provide some additional saproxylic resources, but there is currently little evidence to suggest that this will provide decaying timber of sufficient quality to satisfy the more demanding specialist species. Given that the National Parks Board maintains more than a million roadside trees, there certainly is room for planting the surrounding land with more appropriate native trees or at least non-native trees that are phylogenetically quite related to native plants and managing them in the long term to produce old growth.

Finally, there is currently a lack of comprehensive overview of insects needing conservation attention. While there are doubts about the value of listing enormous numbers of species because the list rapidly becomes far too long to handle with limited logistic support, certain attractive focal species should be chosen to engender public goodwill. Both Cerambycidae and Buprestidae are some of the possible insect groups that represent certain functional (i.e. saproxylic) aspects of biodiversity, and they are highly visible and have aesthetic appeal. It is recommended that a number of rare or declining saproxylic beetles be chosen as focal species and thereby act as umbrellas for awareness about the less conspicuous saproxylic insects. 
ACKNOWLEDGEMENTS. The survey was conducted under the title 'Study of beetle diversity as part of the Bukit Timah Nature Reserve Survey', permit number NP/RP15-042 issued by the National Parks Board. The participants in the survey were Dr Cheong Loong Fah (Team leader), Sean Yap and Robin Ngiam Wen Jiang.

\section{References}

Austin, A.D. \& Dowton, M. (2000). The Hymenoptera: an introduction. In: Austin, A.D. \& Dowton, M. (eds) Hymenoptera: Evolution, Biodiversity and Biological Control, pp. 3-7. Collingwood, Victoria, Australia: CSIRO Publishing.

Basset, Y., Hammond, P.M., Barrois, H., Holloway, J.D. \& Miller, S.E. (2003). Vertical stratification of arthropod assemblages. In: Basset, Y., Novotný, V., Miller, S.E. \& Kitching, R.L. (eds) Arthropods of Tropical Forests: Spatio-Temporal Dynamics and Resource Use in the Canopy, pp. 17-27. Cambridge: Cambridge University Press.

Bellamy, C.L. (2008). A world catalogue and bibliography of the jewel beetles (Coleoptera: Buprestoidea), vol. 4, Agrilinae: Agrilina through Trachyini. Sofia-Moscow: Pensoft.

Berg, Å., Ehnström, B., Gustafsson, L., Hallingbäck, T., Jonsell, M. \& Weslien, J. (1995). Threat levels and threats to red-listed species in Swedish forests. Conserv. Biol. 9(6): 1629-1633.

Chao, A. (1984). Non-parametric estimation of the number of classes in a population. Scand. J. Stat. 11: 265-270.

Chan, L. \& Davison, G.W.H. (2019). Introduction to the Comprehensive Biodiversity Survey of Bukit Timah Nature Reserve, Singapore, 2014-2018. Gard. Bull. Singapore 71 (Suppl. 1): 3-17.

Chapman, A.D. (2009). Numbers of Living Species in Australia and the World, $2^{\text {nd }}$ ed. Canberra: Australian Biological Resources Study.

Chatterjea, K. (2019). Bukit Timah Nature Reserve: a forest in transition. Gard. Bull. Singapore 71 (Suppl. 1): 419-440.

Clark, J.A. \& May, R.M. (2002) Taxonomic bias in conservation research. Science 297: 191-192.

Coddington, J.A., Griswold, C.E., Silva Davila, D., Penaranda, E. \& Larcher, S.F. (1991). Designing and testing sampling protocols to estimate biodiversity in tropical ecosystems. In: Dudley, E.C. (ed.) The unity of evolutionary biology: Proceedings of the Fourth International Congress of Systematic and Evolutionary Biology, pp. 44-60. Portland, Oregon: Dioscorides Press.

Colwell, R.K. \& Coddington, J.A. (1994). Estimating terrestrial biodiversity through extrapolation. Philos. Trans. R. Soc. B 345: 101-118.

Condit, R. (1996). Defining and mapping vegetation types in mega-diverse tropical forests. Trends Ecol. Evol. 11: 4-5.

Corlett, R.T. (1995). The future. Rain Forest in the City: Bukit Timah Nature Reserve, Singapore. Gard. Bull. Singapore (Suppl. 3): 165-168.

Davies, Z.G., Tyler, C., Stewart, G.B. \& Pullin, A.S. (2007). Are current management recommendations for saproxylic invertebrates effective? A systematic review. Biodiver. Conserv. 17: 209-234.

Davison, G.W.H., Ng., P.K.L., \& Ho, H.C. (eds) (2008). The Singapore Red Data Book: Threatened Plants and Animals of Singapore, $2^{\text {nd }}$ ed. Singapore: The Nature Society (Singapore). 
Deyrolle, H. (1864). Description des Buprestides de la Malaisie recueillés par M. Wallace pendant son voyage dans cet Archipel. Ann. Soc. Entomol. Belg. 8: 1-280, 4 plates.

Erwin, T.L. (1982). Tropical forests: their richness in Coleoptera and other arthropod species. Coleopt. Bull. 36: 74-75.

Floren, A. \& Linsenmair, K.E. (1998). Non-equilibrium communities of Coleoptera on trees in a lowland rain forest of Borneo. Ecotropica 4: 55-67.

Floren, A. \& Linsenmair, K.E. (2003). How do beetle assemblages respond to anthropogenic disturbance? In: Basset, Y., Novotny, V., Miller, S.E., \& Kitching, R.L. (eds) Arthropods of tropical forests. Spatio-temporal dynamics and resource use in the canopy, pp. 190-197. Cambridge: Cambridge University Press.

Foottit, R.G. \& Adler, P.H. (2017). Insect Biodiversity: Science and Society, vol. 1, $2^{\text {nd }}$ ed. John Wiley \& Sons Ltd.

Gaston, K.J. (1993). Spatial patterns in the description and richness of the Hymenoptera. In: LaSalle, J. \& Gauld, I.D. (eds) Hymenoptera and Biodiversity, pp. 277-293. Wallingford, UK: CAB International.

Grove, S.L. (2002). Saproxylic insect ecology and the sustainable management of forests. Ann. Rev. Ecol. Syst. 33: 1-23.

Hanski, I. \& Hammond, P. (1995). Biodiversity in boreal forests. Trends Ecol. Evol. 10: 5-6.

Janzen, D.H. (1988). Ecological characterization of a Costa Rican dry forest caterpillar fauna. Biotropica 20(2): 120-135.

Köhler, F. (2000). Totholzkäfer in Naturwaldzellen des nördlichen Rheinlands: Vergleichende Studien zur Totholzkäferfauna Deutschlands und deutschen Naturwaldforschung: Naturwaldzellen, teil 7. Schriftenreihe der Landesanstalt für Ökologie, Bodenordnung und Forsten, Landesamt für Agrarordnung, Nordrhein-Westfalen, bd. 18. Recklinghausen: Landesanstalt für Ökologie, Bodenordnung und Forsten [etc.].

Lindenmayer, D.B., Laurance, W. \& Franklin, J. (2012). Global decline in large old trees. Science 338: 1305-1306.

Novotny, V., Basset, Y., Miller, S.E., Weiblen, G.D., Bremer, B., Cizek, L. \& Drozd, P. (2002). Low host specificity of herbivorous insects in a tropical forest. Nature 416: 841-844.

Obenberger, J. (1924). A study of the Buprestidae, collected by Charles Fuller Baker in Singapore, Borneo and the Philippine Islands. Philipp. J. Sci. 25: 539-660.

Obenberger, J. (1929a). Revision des espèces exotiques du genre Trachys Fabr. du continent asiatique. Přehled exotických druhů rodu Trachys africké pevniny. Acta Entomol. Musei Natl. Pragae 7: 5-106.

Obenberger, J. (1929b). Insecta Baumiana I. 1. Buprestidae. Acta Entomol. Musei Natl. Pragae 7: $107-119$.

Ødegaard F. (2000). How many species of arthropods? Erwin's estimate revised. Biol. J. Linn. Soc. 71: 583-597.

Pascoe, F.P. (1864-1869). Longicornia Malayana; or, a Descriptive Catalogue of the Species of the three Longicorn Families Lamiidae, Cerambycidae and Prionidae collected by Mr. A. R. Wallace in the Malay Archipelago. Trans. Entomol. Soc. Lond., $3^{\text {rd }}$ ser., 3: 1-712.

Ranius, T. \& Jansson, N. (2002). A comparison of three methods to survey saproxylic beetles in hollow oaks. Biodivers. Conserv. 11: 1759-1771.

Shirt, D.B. (1987). British Red Data Books: 2. Insects. Peterborough, UK: Nature Conservancy Council. 
Appendix 1. Cerambycid species collected by Alfred Wallace from Bukit Timah

\begin{tabular}{|c|c|}
\hline \# & Species \\
\hline 1 & Acalolepta cariosa (Pascoe, 1866) \\
\hline 2 & Acalolepta defector (Pascoe, 1866) \\
\hline 3 & Acalolepta tarsalis (Pascoe 1866) \\
\hline 4 & Aeolesthes aurifaber White 1853 (=Neocerambyx alexis Pascoe 1869) \\
\hline 5 & Amechana nobilis Thomson 1864 \\
\hline 6 & Astathes purpurea Pascoe, 1857 \\
\hline 7 & Astathes terminata Pascoe, 1857 \\
\hline 8 & Atimura punctissima Pascoe 1865 \\
\hline 9 & Bacchisa albicornis (Pascoe 1867) \\
\hline 10 & Bacchisa melanura (Pascoe 1867) \\
\hline 11 & Bacchisa nigriventris (Thomson 1865) \\
\hline 12 & Batocera thomsonii Javet 1858 \\
\hline 13 & Cacia confusa Pascoe 1857 \\
\hline 14 & Cacia inculta Pascoe 1857 \\
\hline 15 & Cacia newmanni (Pascoe 1857) \\
\hline 16 & Cereopsius sexnotatus Thomson 1865 \\
\hline 17 & Ceresium raripilum Newman 1842 \\
\hline 18 & Chloridolum ceycinum Pascoe 1869 \\
\hline 19 & Chloridolum thomsoni Pascoe 1859 \\
\hline 20 & Chlorophorus decoratus (Pascoe 1869) \\
\hline 21 & Chlorophorus torquilla (Pascoe 1869) \\
\hline 22 & Choeromorpha irrorata (Pascoe 1857) \\
\hline 23 & Choeromorpha polynesa (White 1856) \\
\hline 24 & Cleomenes dihammaphoroides Thomson 1864 \\
\hline 25 & Clytellus westwoodii Pascoe 1857 \\
\hline 26 & Clytus solitarius Pascoe 1869 \\
\hline 27 & Collyrodes lacordairei Pascoe 1866 \\
\hline 28 & Cylindrepomus laetus Pascoe 1858 \\
\hline 29 & Demodes frenata (Pascoe 1857) \\
\hline 30 & Demonax cumulosus Pascoe 1869 \\
\hline 31 & Demonax macilentus Chevrolat 1858 \\
\hline 32 & Demonax ordinatus Pascoe 1869 \\
\hline
\end{tabular}


Appendix 1. Continuation.

\section{\# $\quad$ Species}

33 Demonax salutarius Pascoe 1869

34 Demonax viverra Pascoe 1857

$35 \quad$ Dialeges pauper Pascoe 1857

36 Diexia punctigera Pascoe 1865

$37 \quad$ Driopea clytina Pascoe 1858

38 Dymascus porosus Pascoe 1865

39 Dystasia semicana Pascoe 1864

$40 \quad$ Ebaeides exigua Pascoe 1864

$41 \quad$ Egesina rigida Pascoe 1864

$42 \quad$ Elacomia femorata (Pascoe 1869)

43 Elydnus amictus Pascoe 1869

$44 \quad$ Eoporis elegans Pascoe 1864

$45 \quad$ Epania brevipennis Pascoe 1869

$46 \quad$ Epania pusio Pascoe 1869

$47 \quad$ Epania singaporensis Thomson 1857

48 Epepeotes lateralis Guérin-Méneville, 1831

49 Epianthe funesta Pascoe 1869

$50 \quad$ Epipedocera cruentata Pascoe 1858

51 Euryclelia cardinalis (Thomson 1864)

52 Euryphagus lundii Fabricius 1792 (=Euryphagus maxillosus Oliver 1795)

53 Exocentrus moerens Pascoe 1864

$54 \quad$ Glenea algebraica Thomson 1857

55 Glenea anticepunctata Thomson 1857 (= G. ianthe)

56 Glenea citrina Thomson 1865

$57 \quad$ Glenea cleome Pascoe 1867

$58 \quad$ Glenea clytoides (Pascoe 1867)

$59 \quad$ Glenea coris Pascoe 1867

60 Glenea dimidiata dimidiata Fabricius 1801

61 Glenea discoidalis Pascoe 1867

$62 \quad$ Glenea extensa Pascoe 1858

63 Glenea funerula Thomson 1857

$64 \quad$ Glenea illuminata Thomson 1857 
Appendix 1. Continuation.

\section{\# $\quad$ Species}

65 Glenea interrupta interrupta Thomson 1860

66 Glenea irene Pascoe 1867 (= G. illuminata (Gahan 1897))

67 Glenea juno Thomson 1865

68 Glenea mathematica anona Pascoe 1867 (=Glenea mathematica alysson 1866)

69 Glenea mesoleuca Pascoe 1867

$70 \quad$ Glenea myrrhis Pascoe 1867

$71 \quad$ Glenea myrsine Pascoe 1867

72 Glenea novemguttata (Laporte de Castelnau 1840)

73 Glenea nympha Thomson 1865

$74 \quad$ Glenea palliata Pascoe 1867

75 Glenea pulchella Pascoe 1858 (=Glenea vesta Pascoe 1866)

76 Glenea scalaris Thomson 1865

77 Glenea voluptuosa Thomson 1860

$78 \quad$ Gnoma longicollis Fabricius 1787

$79 \quad$ Gnoma sticticollis Thomson 1857

$80 \quad$ Grammoechus polygrammus Thomson 1864

81 Hoplocerambyx aramis Thomson 1865

82 Imantocera plumosa (Oliver 1792)

83 Imbrius ephebus Pascoe 1866

84 Isosceles macilenta Newman 1842

$85 \quad$ Laelida antennata Pascoe 1866

$86 \quad$ Menesia pulchella (Pascoe 1867)

$87 \quad$ Merionoeda acuta Pascoe 1866

88. Merionoeda brachyptera Pascoe 1869

89 Mesosa (Saimia) albidorsalis (Pascoe 1865)

$90 \quad$ Myagrus vinosus (Pascoe 1866)

$91 \quad$ Noemia flavicornis Pascoe 1857

$92 \quad$ Noserius tibialis Pascoe 1857

93 Notomulciber (Micromulciber) biguttatus (Pascoe, 1867)

$94 \quad$ Nyctimenius tristis (Fabricius, 1793)

$95 \quad$ Oberea clara Pascoe 1866

96 Oberea compta Pascoe 1867 (= Oberea macrocera Pascoe 1867) 
Apendix 1. Continuation.

\section{\# $\quad$ Species}

97 Oberea denominata Plavilstshikov 1926 (=Oberea limbata Pascoe 1867)

$98 \quad$ Oberea praedita Pascoe 1867

99 Oberea rubetra Pascoe 1858 (=Oberea lusciosa Pascoe 1867)

100 Ocalemia vigilans Pascoe 1858

101 Olenecamptus bilobus Fabricius 1801

102 Olenecamptus optatus Pascoe 1866

103 Paracyriothasastes marmoreus (Pascoe 1857)

104 Peribasis helenor Newman 1851 (=Monohammus aspersus Pascoe, 1856)

105 Peribasis pubicollis Pascoe 1866

106 Pharsalia duplicata Pascoe 1866

107 Planodes deterrens Pascoe 1865

108 Plutonesthes amoena Pascoe 1869

109 Prothema humeralis Pascoe 1866

110 Pseudoparanaspia lepturoides (Pascoe 1869)

111 Pseudozelota capito (Pascoe 1865)

112 Pterolophia melanura (Pascoe 1857)

113 Remphan hopei Waterhouse 1832

114 Schoenionta necydaloides (Pascoe 1867)

115 Schoenionta strigosa (Pascoe 1867)

116 Sclethrus malayanus Niisato 2009

117 Serixia apicalis Pascoe 1857

118 Serixia longicornis Pascoe 1858

119 Serixia nigripes (Pascoe 1858) (=Xyaste subminiacea Pascoe 1867)

120 Serixia paradoxa (Pascoe 1867)

121 Sesiosa subfasciata Pascoe 1865

122 Similosodus verticalis (Pascoe 1864)

123 Stenochroma punctigera (Pascoe 1869)

124 Stromatium longicorne Newman 1842 (=Stromatium asperulum White 1855)

125 Sybra arator Pascoe 1865

126 Tetraommatus nigriceps Pascoe 1869

127 Tetraophthalmus contentiosus (Pascoe, 1867)

128 Typodryas chalybeata Pascoe 1866 (=Psalanta chalybeata Pascoe 1869) 
Appendix 1. Continuation.

\begin{tabular}{ll}
\hline$\#$ & Species \\
\hline 129 & Xenolea tomentosa (Pascoe 1864) \\
130 & Xoanodera trigona Pascoe 1857 \\
131 & Xylotrechus buqueti (Laporte et Gory 1836) \\
132 & Xylotrechus javanicus Laporte et Gory 1841 \\
133 & Zoodes cornutus Lacordaire 1869 \\
\hline
\end{tabular}

Appendix 2. Buprestid species collected by Alfred Wallace from Bukit Timah

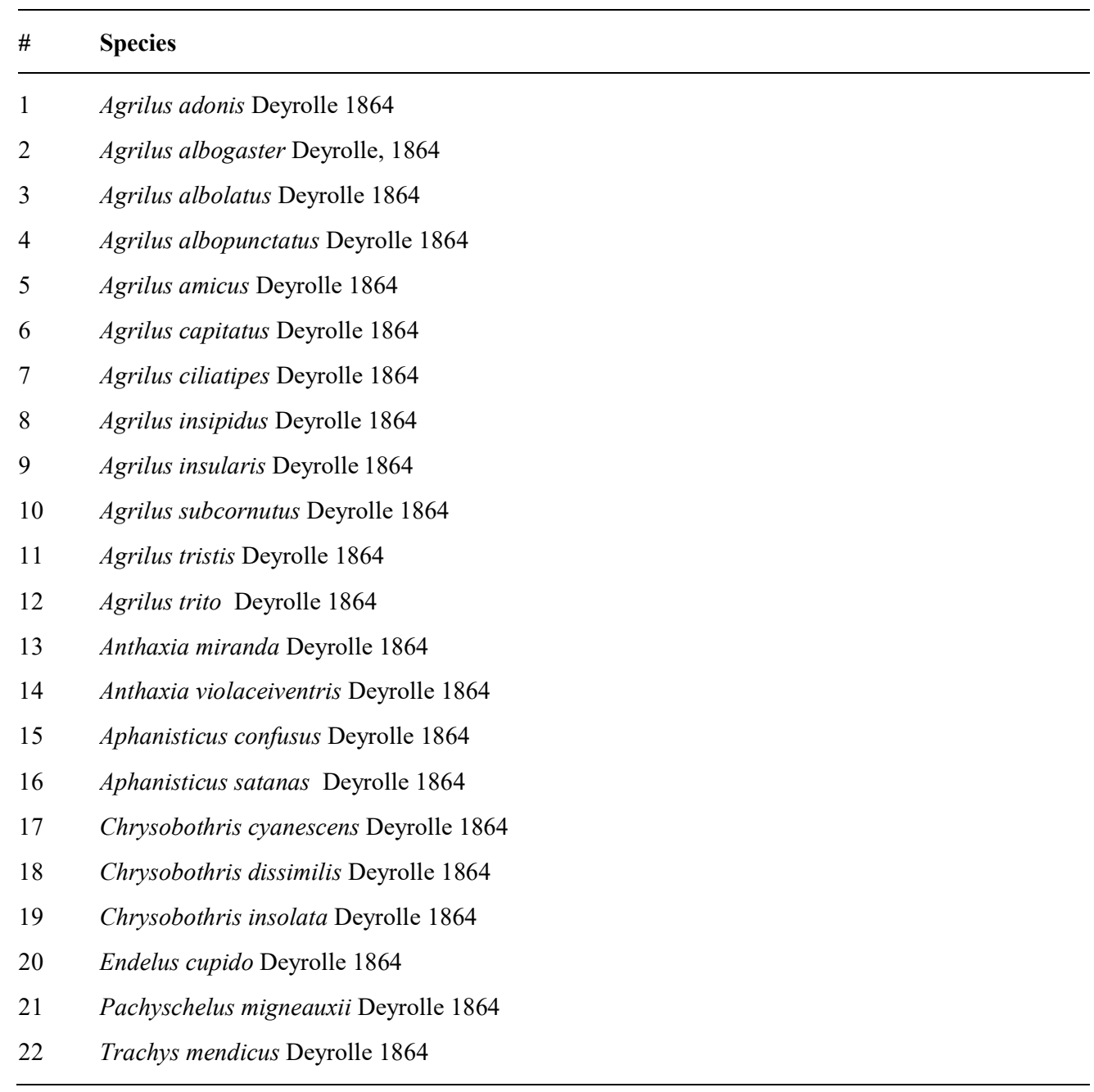

